\title{
A EFETIVIDADE DO DIREITO HUMANO À ALIMENTAÇÃO ADEQUADA ÀS PESSOAS PRIVADAS DE LIBERDADE NOS CÁRCERES BRASILEIROS E O PAPEL DAS INSTITUIÇÕES DE JUSTIÇA
}

\author{
*José Augusto Magni Dunck \\ **Nivaldo dos Santos
}

\section{Resumo:}

Discute-se a eficácia da positivação do direito humano à alimentação adequada na realidade das pessoas privadas de liberdade nos cárceres brasileiros, visto que o fracasso do Estado em garantir a fruição do direito à alimentação a todos é uma falha séria na agenda dos direitos humanos. O objetivo é problematizar o direito à alimentação, a ausência de políticas públicas específicas para este grupo institucionalizado no âmbito do Sistema Nacional de Segurança Alimentar e a responsabilidade das Instituições de Justiça na concretização desse direito fundamental. Apropria-se do método dialético com abordagem exploratória e reflexiva sobre bibliografia, legislação e relatórios oficiais.

Palavras-chave: Direito humano à alimentação adequada; efetividade; pessoas privadas de liberdade; instituições de justiça.

\section{THE ROLE OF JUSTICE INSTITUTIONS IN REALIZING THE HUMAN RIGHT TO ADEQUATE FOOD FOR PERSONS DEPRIVED OF THEIR LIBERTY IN THE CONTEXT OF THE DEMOCRATIC STATE OF LAW}

\begin{abstract}
:
The effectiveness of the human right to adequate food in the reality of persons deprived of their liberty is discussed, since the failure of the State to guarantee the enjoyment of the right to food for all is a serious flaw in the human rights. The objective is to problematize the right to food, the absence of specific public politics within the scope of the National Food Security System and the responsibility of the Justice Institutions in the realization of this fundamental right. It appropriates the dialectical method with an exploratory and reflexive approach to bibliography, legislation and official reports
\end{abstract}

Keywords: Human right to adequate food; effectiveness; persons deprived of their liberty; institutions of justice.

\footnotetext{
* Especialista em Criminologia e Segurança Pública (UFG), mestrando em Direito Agrário (UFG), professor universitário, tem experiência na área do Direito, com ênfase em ciências criminais, com interesse principal em segurança pública e direitos humanos. Contato: Rua 53, 280, Jardim Goiás, Goiânia - Goiás, CEP 74.810-210, dunckmagni@gmail.com.

** Doutor em Direito (PUC SP), professor universitário, tem experiência na área de Direito, com ênfase em Teoria do Estado, com atuação principal em acesso à justiça, direito público, estado, constitucional, propriedade intelectual e atividades agrárias e ambientais. Contato: Rua 53, 285, Jardim Goiás, Goiânia - Goiás, CEP 74.810-210, nivaldodossantos@bol.com.br
} 


\section{A EFETIVIDADE DO DIREITO HUMANO À ALIMENTAÇÃO ADEQUADA ÀS PESSOAS PRIVADAS DE LIBERDADE NOS CÁRCERES BRASILEIROS E O PAPEL DAS INSTITUIÇÕES DE JUSTIÇA}

\section{Introdução}

O direito humano à alimentação adequada é tema instigante que principia bastante fascínio, seja diante do processo de sua construção histórica até a recente inclusão no rol dos direitos sociais, que suscita discussões sobre seu significado e alcance, seja pelo desafio de sua concretização social, especialmente para grupos sociais minoritários, a exemplo das pessoas privadas de liberdade.

Diante de tantas perceptivas, adota-se a abordagem sobre o significado desse direito e sua concretização no cárcere.

A pesquisa tem como objetivo problematizar o significado do direito à alimentação, a ausência de políticas públicas específicas no âmbito do Sistema Nacional de Segurança Alimentar e Nutricional para concretização desse direito para as pessoas privadas de liberdade, bem como problematizar a responsabilidade das Instituições de Justiça na concretização desse direito fundamental e apresentar a realidade observada no sistema prisional no que diz respeito ao direito social à alimentação.

O método usado é o dialético com abordagem exploratória sobre bibliografia, legislação e dados oficiais sobre a temática. Em seguida, diante dos dados observados, realiza-se abordagem relacional reflexiva.

O artigo é organizado em três tópicos. O primeiro aborda o processo de construção histórica e o sentido do direito à alimentação, o que significa sua positivação na legislação brasileira, no cárcere, e instrumentos para a concretização social. Tal enfoque possibilita aferir a extensão do direito, modo de concretização e a existência de políticas públicas específicas de efetividade para as pessoas privadas de liberdade.

No segundo tópico é abordada a situação da efetividade desse direito para as pessoas privadas de liberdade nos presídios brasileiros, por meio de relatório realizado no período de 2010 a 2011, de modo esclarecer quais variáveis impedem, ou contribuem, para efetivação.

No último é discutido o papel das Instituições de Justiça na concretização do direito à alimentação das pessoas privadas de liberdade no contexto do Estado Democrático de Direito diante da reafirmação do direito à alimentação na legislação brasileira, no âmbito legal e constitucional.

Algumas variáveis podem obstar a concretização do direito à alimentação das

pessoas privadas de liberdade e, dentre elas, o racismo institucional será ligeiramente problematizado. 


\section{Síntese do processo de construção histórica do direito humano à alimentação adequada e sua positivação na legislação brasileira}

Durante os anos de 1940 e 1990 várias mudanças e processos políticos marcaram o curso do paradigma de segurança alimentar, inclusive o processo de criação da Organização das Nações Unidas para Alimentação e a Agricultura (FAO) nas Nações Unidas (ONU), em 1944, em Quebec (TOMAZINI; LEITE, 2015, p. 18).

A elaboração jurídica desse paradigma, corolário do direito humano à alimentação adequada, encontra-se em movimento progressivo e era interpretado, de início, como direito a um adequado nível de vida. Nessa perspectiva, no âmbito da prática internacional, a consciência europeia despertou (ZIEGLER, 2012, p. 82) depois dos horrores da Segunda Guerra Mundial, em contextos de conflitos armados, foi defendido como direito fundamental, econômico e social do ser humano, bem como de segurança nacional, no caso de destruição em massa de alimentos (MALUF; MENEZES apud TAKAGI 2006, p.12) e tem inspirado a formulação de várias políticas públicas de acesso à alimentação (VALENTE, 2002, p. 18).

No Brasil, ainda antes deste período, o pesquisador Josué de Castro ${ }^{1}$, médico e geógrafo pernambucano, em “Alimentação e Raça” (1935), “Geopolítica da Fome” (1946), dentre outros, discute o tema fome e conclui que a subalimentação e a má nutrição persistentes perturbavam profundamente as sociedades em seu conjunto, quer os famintos, quer os saciados, que metade da população brasileira não dormia porque tinha medo daqueles que passavam fome. Alertava que a fome torna impossível a construção de uma sociedade pacificada e asseverava que em um País no qual uma parte importante da população está atormentada pela angústia em face do amanhã, a paz social só é viável mediante a repressão. Que a questão da fome é, além de tudo, uma questão política (CASTRO, 1946, apud ZIELGLER, 2010, p. 89).

Ao longo de sua obra Castro explícita o caráter político e social da fome e suas consequências e exige resolução para questão. É expulso do Brasil, considerado subversivo, em 1964, quando representava seu País na ONU. Morre no exílio, em 1973, em Paris, e simboliza a luta contra a fome que a elite brasileira, à época da Ditadura Civil-Militar, incansavelmente tentava ocultar (VALENTE, 2002, p. 44).

\footnotetext{
${ }^{1}$ Josué de Castro foi presidente da FAO, em 1952 e 1956, e indicado duas vezes ao Prêmio Nobel da Paz.
} 


\section{A EFETIVIDADE DO DIREITO HUMANO À ALIMENTAÇÃO ADEQUADA ÀS PESSOAS PRIVADAS DE LIBERDADE NOS CÁRCERES BRASILEIROS E O PAPEL DAS INSTITUIÇÕES DE JUSTIÇA}

Internacionalmente, o processo de construção do conceito de direito humano à alimentação adequada passa por vários instrumentos internacionais vinculativos e orientadores.

Dentre eles destaca-se a Declaração Universal de Direitos Humanos (1948), artigo 25²; Declaração Universal sobre a Erradicação da Fome e Desnutrição (1974); Declaração de Roma sobre a Segurança Alimentar Mundial (1996) e Diretrizes Voluntárias em apoio à realização progressiva do direito à alimentação adequada no contexto da segurança alimentar nacional (2004). Esses instrumentos não são vinculantes, mas expressam princípios de grande valor moral, histórico e orientadores às nações.

Dentre os vinculantes, que obrigam os Estados Signatários, inclusive o Brasil, encontram-se o Pacto Internacional Sobre Direitos Econômicos, Sociais e Culturas (1966), artigo $11^{3}$, promulgado pelo Decreto n. ${ }^{\circ}$ 591, de 06 de julho de 1992 (marco normativo no País); a Convenção sobre a Eliminação de Todas as Formas de Discriminação contra a Mulher (1981), preâmbulo ${ }^{4}$, promulgada pelo Decreto n. ${ }^{\circ} 4.377$, de 13 de setembro de 2002; Convenção dos Direitos da Criança (1989), artigo 24, 2, c $^{5}$, promulgada pelo Decreto n. ${ }^{\circ}$ 99.710, de 21 de novembro de 1990, dentre outros, que ratificam no plano universal dos direitos humanos o direito à alimentação.

Ainda que o direito humano à alimentação adequada esteja normatizado em vários textos internacionais, é tratado com mais abrangência no Pacto Internacional sobre Direitos Econômicos, Sociais e Culturais (PIDESC).

Após a divulgação do PIDESC, na década de 1970, a crise alimentar decorrente da crise econômica mundial fortalece a politização do tema alimentação. Reações à crise originaram a I Conferência Mundial de Alimentação, em Roma, de iniciativa da FAO, em

\footnotetext{
${ }^{2}$ Toda a pessoa tem direito a um nível de vida suficiente para lhe assegurar e à sua família a saúde e o bem-estar, principalmente quanto à alimentação, ao vestuário, ao alojamento, à assistência médica e ainda quanto aos serviços sociais necessários, e tem direito à segurança no desemprego, na doença, na invalidez, na viuvez, na velhice ou noutros casos de perda de meios de subsistência por circunstâncias independentes da sua vontade.

${ }^{3}$ Os Estados Partes do presente Pacto reconhecem o direito de toda pessoa a um nível de vida adequando para si próprio e sua família, inclusive à alimentação, vestimenta e moradia adequadas, assim como a uma melhoria continua de suas condições de vida. Os Estados Partes tomarão medidas apropriadas para assegurar a consecução desse direito, reconhecendo, nesse sentido, a importância essencial da cooperação internacional fundada no livre consentimento.

${ }^{4}$ Preocupados com o fato de que, em situações de pobreza, a mulher tem um acesso mínimo à alimentação, à saúde, à educação, à capacitação e às oportunidades de emprego, assim como à satisfação de outras necessidades. ${ }^{5}$ Os Estados Partes garantirão a plena aplicação desse direito e, em especial, adotarão as medidas apropriadas com vistas a: [...]c) combater as doenças e a desnutrição dentro do contexto dos cuidados básicos de saúde mediante, inter alia, a aplicação de tecnologia disponível e o fornecimento de alimentos nutritivos e de água potável, tendo em vista os perigos e riscos da poluição ambiental;
} 
1974, que consagra a chamada "Revolução Verde" e reforça o capital ideológico e político para implantação do padrão agrícola de emprego intensivo de fertilizantes, agrotóxicos, sementes melhoradas e máquinas agrícolas com vistas a alta produção de alimentos (TAKAGI, 2006, p.13).

Neste contexto da crise de escassez de 1972-4, o tema da alimentação, da segurança alimentar, é tratado como questão de produção de alimentos e perde-se o foco como direito humano. A partir da década de 1980, percebe-se que, superada a crise alimentar, a fome e a subnutrição têm origem, principalmente, na dificuldade de acesso aos alimentos. A segurança alimentar somente poderia ser garantida com políticas de redistribuição de recursos materiais, renda e redução da desigualdade social. Portanto, deste este período até 1990, o significado do direito à alimentação se relaciona com o direito à vida, autodeterminação e satisfação de outras necessidades básicas (VALENTE, 2002, p. 41).

A luta contra a fome e a construção da segurança alimentar e nutricional no Brasil é observada juntamente com a luta pela democratização do País e as primeiras referências a segurança alimentar, em nível institucional, é do final de 1985 com o movimento da sociedade civil. Cria-se uma proposta de "Política Nacional de Segurança Alimentar", com a criação do Conselho Nacional de Segurança Alimentar (Consea). Na década de 1990, aparece a organização social “Ação para Cidadania contra a Fome, a Miséria e pela Vida" liderada pelo sociólogo Herbert de Souza, conhecido como Betinho (TOMAZINI; KEITE, 2015, p. 20). Na mesma época, o Partido dos Trabalhadores elabora proposta de política nacional de segurança alimentar, rejeitada pelo governo Collor, e reapresentada ao Governo Itamar Franco, que cria por decreto o Consea. No governo Fernando Henrique Cardoso o Consea é extinto e cria-se o Conselho da Comunidade Solidária com ênfase mais em processos de exclusão econômica e social, diluindo-se o tema da segurança alimentar em outros temas. Em seguida, fóruns, debates e programa governamentais foram realizados sobre tema (VALENTE, 2002, p. 45).

Na Cúpula Mundial de Alimentação (1996), em Roma, promovida pela Organização das Nações Unidas para Alimentação e a Agricultura (FAO), participaram centenas de países, inclusive o Brasil e Comunidade Europeia, que elaboraram a Declaração de Roma sobre Segurança Alimentar.

$\mathrm{Na}$ ocasião os países assumiram compromissos para reafirmar "o direito de todos a terem acesso a alimentos seguros e nutritivos, em consonância com o direito a uma 


\section{A EFETIVIDADE DO DIREITO HUMANO À ALIMENTAÇÃO ADEQUADA ÀS PESSOAS PRIVADAS DE LIBERDADE NOS CÁRCERES BRASILEIROS E O PAPEL DAS INSTITUIÇÕES DE JUSTIÇA}

alimentação adequada e com o direito fundamental de todos a não sofrer a fome ${ }^{6 "}$.

No Plano de Ação, dentre os objetivos estabelecidos estava o de esclarecer o sentido e alcance do direito à alimentação e a elaboração de uma estratégia coordenada para sua implementação. Tal esclarecimento foi objeto do Comentário Geral n. ${ }^{\circ}$ 12, de 12 de maio de 19997 , sobre o artigo 11 do PIDESC, adotado pelo Comitê para Direitos Econômicos, Sociais e Culturais (EIDE, 2002, p. 209).

Dentre as metas do Plano de Ação da Declaração de Roma, estava fixada a redução pela metade, entre 1996 e 2015, a proporção da população que sofre de fome ${ }^{8}$.

Em 2003, três era as diretrizes da agenda da Segurança Alimentar e Nutricional: a) Fome Zero (PFZ) ${ }^{9}$ e programas afins implementados pelo Governo Federal e demais esferas de governo; b) Conselho Nacional de Segurança Alimentar e Nutricional (CONSEA) e seus congêneres estaduais; c) As proposições, projetos e outras iniciativas oriundas das organizações da sociedade civil, dos movimentos e redes sociais (MALUF, 2006, 19).

O Programa Fome Zero (PFZ) é lançado, em 2003, no governo Lula, em substituição ao Programa Comunidade Solidária, instituído por Cardoso, em 1995. O programa era bastante amplo e visava atender bairros carentes, assentamentos agrários, restaurantes populares, bancos de alimentos, transferências condicionadas à frequência escolar etc. $\mathrm{O}$ objetivo promover a Segurança Alimentar para garantir o direito humano à alimentação em conjunto com todos os governos e a sociedade civil. O programa foi reconhecido internacionalmente como referência de política pública, mas foi incorporado, em 2004, ao Programa Bolsa Família (TOMAZINI; LEITE, 2015, p. 23).

Segundo estudiosos do tema ${ }^{10}$ o Programa Bolsa Família tornou-se grande instrumento de garantia do direito humano à alimentação a muitas famílias pobres brasileiras

\footnotetext{
${ }^{6}$ Preâmbulo da Declaração de Roma Sobre a Segurança Alimentar. Cúpula Mundial da Alimentação (1996). Organização das Nações Unidas para Alimentação e a Agricultura (FAO). Disponível em: <http://www.fao.org/docrep/003/w3613p/w3613p00.htm>. Acesso em: 8.ago.2017.

7 Disponível em: <http://fianbrasil.org.br/wp-content/uploads/2016/12/Comentario-Geral-No-12.pdf>. Acesso em: 08. ago.2017.

${ }^{8}$ Em 30 de novembro de 2014, o Brasil, junto com Camarões e Uruguai, foi premiado pela Organização das Nações Unidas para a Agricultura e Alimentação (FAO), por cumprir a meta proposta, em reduzir à metade o número absoluto de pessoas subalimentada. ONU. Nações Unidas no Brasil. Brasil ganha prêmio da FAO pela luta contra a fome. Disponível em: <https://nacoesunidas.org/brasil-ganha-premio-da-fao-pela-luta-contra-afome-solenidade-sera-em-roma-neste-domingo-30/ >. Acesso em: 08. ago. 2017.

${ }^{9} \mathrm{O}$ objetivo principal do PFZ era garantir o direito humano à alimentação por meio da promoção da Segurança Alimentar, compondo ações e programas articulados pelo Governo Federal com estados, municípios e sociedade civil e durou de 2002 a 2003, quando foi incorporado ao Programa Bolsa Família (TOMAZINI; LEITE, 2015).

10 (ZIMMERMANN, 2006) e (FARIA; SILVA 2016).
} 
Verifica-se, então, que "a segurança alimentar se consolidou como um paradigma de política pública ao longo dos anos 1990 para introduzir-se de modo significativo, no Brasil, na agenda do governo federal em 2003" (TOMAZINI; LEITE, 2015). E somente a partir deste período iniciou-se um processo de construção de uma agenda nacional de institucionalização da segurança alimentar e nutricional como política de Estado, cuja conversão em política nacional dependeria dos governos e da sociedade, sendo relevante a aprovação da Lei Orgânica de Segurança Alimentar e Nutricional (LOSAN) que criava o Sistema Nacional de Segurança Alimentar e Nutricional (SISAN) que tramitava no Congresso Nacional (MALUF, 2006, p. 19).

O Projeto de Lei n. ${ }^{\circ}$ 6.047/2005 é aprovado e transformado na Lei n. ${ }^{\circ}$ 11.346/2006, conhecida como Lei Orgânica da Segurança Alimentar e Nutricional (Losan), que cria o Sistema Nacional de Segurança Alimentar e Nutricional - SISAN com vistas em assegurar o direito humano à alimentação adequada.

A aprovação da lei significa a institucionaliza da política de segurança alimentar e nutricional no País, tendo como órgão central o Conselho Nacional de Segurança Alimentar e Nutricional (Consea) e os Conselhos Estaduais e Municipais, como órgãos descentralizados, composto por representantes de todas as esferas de governo e civis, com atribuições de incentivar a elaboração de políticas públicas voltadas para área.

Em âmbito constitucional, a Proposta de Emenda à Constituição n. ${ }^{\circ}$ 47/2003 ganha força após à aprovação da Losan e se transforma na Emenda à Constituição n. ${ }^{\circ}$ 64, promulgada em 2010, que reconhece a alimentação como direito social fundamental que passa a constar no caput do artigo $6^{\circ}$ da Constituição Federal de 1988.

A Lei Orgânica de Segurança Alimentar e Nutricional (Lei 11.346/2006) define segurança alimentar e nutricional como a realização do direito de todos ao acesso regular e permanente a alimentos de qualidade, em quantidade suficiente, sem comprometer o acesso a outras necessidades essenciais, tendo como base práticas alimentares promotoras de saúde que respeitem a diversidade cultural e que sejam ambiental, cultural, econômica e socialmente sustentáveis $\left(\operatorname{artigo} 3^{\circ}\right)$.

Desse modo, a alimentação adequada é definida como direito fundamental do ser humano, inerente à dignidade da pessoa humana e indispensável à realização dos direitos consagrados na Constituição Federal, devendo o poder público adotar as políticas e ações que se façam necessárias para promover e garantir a segurança alimentar e nutricional da população (artigo $2^{\circ}$ ).

A alimentação é reconhecida como direito humano positivado na legislação do País 


\section{A EFETIVIDADE DO DIREITO HUMANO À ALIMENTAÇÃO ADEQUADA ÀS PESSOAS PRIVADAS DE LIBERDADE NOS CÁRCERES BRASILEIROS E O PAPEL DAS INSTITUIÇÕES DE JUSTIÇA}

deste 1992, por força do Decreto n. ${ }^{\circ}$ 591, que promulga o Pacto Internacional Sobre Direitos Econômicos, Sociais e Culturas (1966) que trata do direito à alimentação no artigo 11, corroborado no artigo $2^{\circ}$ da Lei Federal n. ${ }^{\circ} 11.346 / 2206$ e no artigo $6^{\circ}$, caput, da Constituição Federal de 1988, alterada pela Emenda Constitucional n. ${ }^{\circ}$ 64/2010.

A Lei 11.346/2006, institucionaliza a política de garantia da segurança alimentar e nutricional ao criar o Sistema Nacional de Segurança Alimentar e Nutricional (Sisan).

O sistema tem como princípio a universalidade e equidade no acesso à alimentação adequada, sem qualquer espécie de discriminação; a preservação da autonomia e respeito à dignidade das pessoas; a participação social na formulação, execução, acompanhamento, monitoramento e controle das políticas e dos planos de segurança alimentar e nutricional em todas as esferas de governo; a transparência dos programas, das ações e dos recursos públicos e privados e dos critérios para sua concessão ( $\operatorname{artigo} 8^{\circ}$ ).

As diretrizes básicas do sistema, fixadas na lei (artigo $9^{\circ}$ ), são a promoção da intersetorialidade das políticas, programas e ações governamentais e não-governamentais; a descentralização das ações e articulação, em regime de colaboração, entre as esferas de governo; o monitoramento da situação alimentar e nutricional, visando a subsidiar o ciclo de gestão das políticas para a área nas diferentes esferas de governo; a conjugação de medidas diretas e imediatas de garantia de acesso à alimentação adequada, com ações que ampliem a capacidade de subsistência autônoma da população; a articulação entre orçamento e gestão; e o estímulo ao desenvolvimento de pesquisas e à capacitação de recursos humanos.

Os objetivos do Sisan incluem formular e implementar políticas e planos de segurança alimentar e nutricional, estimular a integração dos esforços entre governo e sociedade civil, bem como promover o acompanhamento, o monitoramento e a avaliação da segurança alimentar e nutricional do País (artigo 10).

Com a criação do Sisan, em 2006, órgão central federal, que visa interagir com todas os entes federados e sociedade civil, com a finalidade de diagnosticar e elaborar políticas públicas específicas visando a concretização do direito humano à alimentação adequada, vislumbra-se, a seguir, no próximo tópico, aferir quais foram as medidas adotadas para efetividade deste direito em relação às pessoas privadas de liberdade que se encontram nos cárceres brasileiros.

\section{Um diagnóstico sobre a alimentação das pessoas privadas de liberdade nos cárceres brasileiros: insegurança alimentar}


As pessoas presas, seja por força de decisão judicial que decreta prisão provisória, ou por condenação a pena privativa de liberdade decorrente de uma sentença penal transitada em julgado, não perdem a dignidade da pessoa humana, somente a liberdade é restringida e os direitos políticos suspensos (art. 15, III, CF/88). “Ao condenado e ao internado serão assegurados todos os direitos não atingidos pela sentença ou pela lei"11.

A legislação que disciplina as normas sobre cumprimento de pena privativa de liberdade, especialmente a Lei n. ${ }^{\circ}$ 7.210, 11 de julho de 1984 (Lei de Execução Penal), explicita vários direitos das pessoas privadas de liberdade, dentre eles o da assistência material (artigo. 12).

A assistência material compreende as necessidades básicas da pessoa, vestuário, alimentação suficiente ${ }^{12}$, incluída água potável, dentre outros.

A competência para legislar sobre "direito penitenciário", no Brasil, é concorrente entre União e Estados (artigo 24, I, CF/88). À União cabe legislar sobre as normas gerais de direito penitenciário e aos Estados suplementar a legislação, adequando-a a sua realidade social, mas sem contrariar a norma geral.

A Lei 7.210/84, norma geral sobre “direito penitenciário", não disciplina a quantidade, qualidade e o modo de fornecimento da alimentação aos presos, cabendo aos Estados tal incumbência.

Em 1994, o Conselho Nacional de Política Criminal e Penitenciária (CNPCP), órgão subordinado ao Ministério da Justiça, responsável por propor diretrizes da política criminal, dentre outras incumbências (art. 64, Lei 7.210/84), aprovou a Resolução n. ${ }^{\circ}$ 14/1994 ${ }^{13}$, onde fixa as regras mínimas para tratamento do preso no Brasil ${ }^{14}$. Segundo a resolução, “a administração do estabelecimento fornecerá água potável e alimentação aos presos" e “a alimentação será preparada de acordo com as normas de higiene e de dieta, controlada por nutricionista, devendo apresentar valor nutritivo suficiente para manutenção da saúde e do vigor físico do preso ${ }^{15}$ ".

\footnotetext{
${ }^{11}$ Artigo $3^{\circ}$ da Lei 7.210/84 (Lei de Execução Penal).

${ }^{12}$ Podendo também adquirir (art. 13), resguarda o direito à alimentação ao egresso, se necessários, pelo prazo de dois meses (art. 25, II).

13 Disponível em: <http://www.justica.gov.br/seus-direitos/politica-penal/cnpcp-1/resolucoes/resolucoesarquivos-pdf-de-1980-a-2015/resolucao-no-14-de-11-de-novembro-de-1994.pdf>. Acesso em: 09 ago. 2017.

${ }^{14}$ Influência da "Regras Mínimas para o Tratamento de Presos" aprovadas em 1955, em Genebra, pelas Nações Unidas.

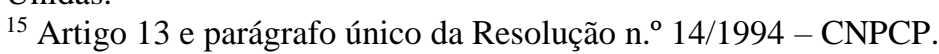




\section{A EFETIVIDADE DO DIREITO HUMANO À ALIMENTAÇÃO ADEQUADA ÀS PESSOAS PRIVADAS DE LIBERDADE NOS CÁRCERES BRASILEIROS E O PAPEL DAS INSTITUIÇÕES DE JUSTIÇA}

Em 2012, o mesmo conselho aprovou a Resolução n. ${ }^{\circ} 02^{16}$, diante da necessidade de assegurar condições dignas durante o transporte e custódia de pessoas presas e internadas, no período de deslocamento, que não estava sendo observadas. Frisou-se a necessidade da Administração do estabelecimento penal fornecer água potável e alimentação suficiente e adequada às pessoas presas ou internadas, no decorrer do deslocamento, levando em consideração o tempo de duração do trajeto e a distância percorrida. Sendo que a alimentação será preparada de acordo com normas nutricionais e de higiene, devendo apresentar valor nutritivo suficiente para manutenção da saúde e do vigor físico da pessoa presa ou internada $\left(\operatorname{artigo} 4^{\circ}\right)$.

Ainda sobre a alimentação, a Resolução n. ${ }^{\circ}$ 04/2009-CNPCP, que disciplina situação de filhos de mulheres encarceradas, dispõe que a alimentação fornecida às crianças de presas devem ser adequadas, conforme sua idade e com diversidade de itens, de acordo com Guia Alimentar das Crianças do Ministério da Saúde no caso de crianças até dois anos e demais recomendações que compõem uma dieta saudável para crianças entre dois a sete anos (artigo $\left.7^{\circ}\right)$.

No âmbito internacional, as "Regras Mínimas para o Tratamento de Presos" aprovadas em 1955 pelas Nações Unidas, foram atualizadas, em 2015, e originaram as "Regras de Mandela"17. Quanto à alimentação, a regra 22, itens1 e 2, dispõem que "todo preso deve receber da administração prisional, em horários regulares, alimento com valor nutricional adequado à sua saúde e resistência, de qualidade, bem preparada e bem servida" e que "todo preso deve ter acesso a água potável sempre que necessitar".

Observa-se que as "Regras de Mandela"18", que explicitam as regras mínimas das nações unidas para o tratamento de presos, corrobora a importância da garantia do direito humano à alimentação adequada para todos, assegurado via Sistema Nacional de Segurança Alimentar e Nutricional.

Diante de tantos marcos normativos resta conhecer qual a realidade da alimentação das pessoas privadas de liberdade nos cárceres brasileiros.

\footnotetext{
16 Disponível em: <http://www.justica.gov.br/seus-direitos/politica-penal/cnpcp-1/resolucoes/resolucoesarquivos-pdf-de-1980-a-2015/resolucao-no-2-de-1o-de-junho-de-2012.pdf>. Acesso em: 09 ago. 2017.

${ }^{17}$ UN - UNITED NATION. Economic and Social Council. United Nations Standard Minimum Rules for the Treatment of Prisoners (the Mandela Rules). Comission on Crime 61 Prevention and Criminal Justice. 24 Session. Viena, 18 - 22 May 2015. E/CN.15/2015/L.6/Rev.1.

18 Diante da diversidade de das condições jurídicas, sociais, econômicas e geográficas, as regras servem de estímulo para o constante empenho na superação das dificuldades práticas que se opõem a sua aplicação.
} 
Segundo dados levantados pelo Conselho Nacional de Justiça (CNJ) nas unidades prisionais do País, no período de 2010-2011, a alimentação dos presos não pode ser considerada adequada ${ }^{19}$.

Nos relatórios oficiais do CNJ a total ausência ou escassez de água potável, a má qualidade ou insuficiência da alimentação fornecida aos presos em várias unidades prisionais do país aparece como regra ${ }^{20}$.

Na compreensão na ideia de alimentação a água potável não pode ser esquecida. Ela é a alimentação mais importante para o organismo humano, mas quase totalmente ausente nas unidades prisionais do País.

Percebe-se que a alimentação das pessoas privadas de liberdade é inadequada, pelo menos tal conclusão é perceptível no período compreendido pela pesquisa do CNJ (2010 a 2011), não sendo garantido o direito humano à alimentação adequada a este grupo de pessoas institucionalizadas.

Desse modo, verifica-se que a positivação ${ }^{21}$ do direito à alimentação não tem grande efetividade na realidade das pessoas privadas de liberdade nos cárceres brasileiros.

Muitas variáveis (corrupção, má gestão etc) impedem a efetividade desse direito para as pessoas privadas de liberdade no sistema prisional do País. Uma delas é o racismo institucional $^{22}$ que destrói a consciência de identidade entre todos os seres humanos e permite que se tolere a destruição de seu semelhante pela fome, mesmo que oculta, sem colocar em risco a própria humanidade, a própria identidade. (ZIEGLER, 2012, p 83).

Diante da ausência de concretização do direito humano à alimentação adequada para as pessoas privadas de liberdade, direito básico que antecede outros direitos, as Instituições de Justiça devem atuar para viabilizar sua efetivação.

\footnotetext{
${ }^{19}$ Conselho Nacional de Justiça. Mutirão carcerário. Raio-X do sistema penitenciário brasileiro. 2012. Disponível em: <http://www.cnj.jus.br/images/pesquisas-judiciarias/Publicacoes/mutirao_carcerario.pdf.> Acesso em: 11 mar. 2017.

${ }^{20} \mathrm{O}$ relatório é mais geral sobre as condições das unidades prisionais, não é específico sobre fornecimento de alimentação às pessoas privadas de liberdade.

${ }^{21}$ Lei de Execução Penal, em 1984, art. 12; Pacto Internacional Sobre Direitos Econômicos, Sociais e Culturas (1966), promulgado no Brasil pelo Decreto n. ${ }^{\circ}$ 591/1992, no artigo 11; Lei 11.346/2006, cria o Sisan, que visa assegurar o direito humano à alimentação adequada a todos; inclusão do direito à alimentação no rol dos direitos sociais fundamentais na Constituição Federal de 1988; edição de várias resoluções que tratam das regras mínimas para tratamento de presos no Brasil, pelo CNPCP, que garante o direito à alimentação.

${ }^{22}$ Sobre o assunto: DUNCK, José Augusto Magni. Direito humano à alimentação adequada como vertente do direito agrário: a (in) eficácia do sistema nacional de segurança alimentar e nutricional na concretização do direito à alimentação das pessoas custodiadas. XXVI ENCONTRO NACIONAL DO CONPEDI BRASÍLIA DF, 2017.
} 


\section{A EFETIVIDADE DO DIREITO HUMANO À ALIMENTAÇÃO ADEQUADA ÀS PESSOAS PRIVADAS DE LIBERDADE NOS CÁRCERES BRASILEIROS E O PAPEL DAS INSTITUIÇÕES DE JUSTIÇA}

3. O papel das "Instituições de Justiça" na concretização do direito humano à alimentação adequada às pessoas privadas de liberdade no contexto do Estado democrático de direito

Antes de problematizar o papel das "Instituições de Justiça" é preciso alcançar o significado do direito à alimentação adequada no âmbito do cárcere, visto que a ideia de alimentação, ou do próprio ato de comer, é exteriorizado distintamente ao longo da história da humanidade e nos diversos territórios do globo.

O que significa, então, alimentar-se adequadamente, no cárcere? A resposta mais adequada a esta questão não pode olvidar o princípio democrático que funda o Estado brasileiro.

Segundo Rocha, a elaboração de uma política pública legítima deve possibilitar a participação de todos os atingidos, "a democracia está diretamente associada ao direito: não basta a participação de todos, é essencial que sejam tratados como livres e iguais. Os procedimentos devem proporcionar que os cidadãos tenham igual possibilidade de participação" (2010, p. 76).

Todos devem participar das discussões da elaboração da política pública, principalmente os atingidos pela medida, "o debate público está diretamente associado à biografia, à história, de vida individual. Com o compartilhamento desse sentimento de exclusão com outros indivíduos há a possibilidade de interferência na esfera pública [...]” (ROCHA, 2010, p. cit.).

No âmbito do Sistema Nacional de Segurança Alimentar e Nutricional estão previstos canais democráticos: a Conferência Nacional de Segurança Alimentar e Nutricional e o Conselho Nacional de Segurança Alimentar e Nutricional (Consea). Resta analisar se o tema é adequadamente discutido nesses canais.

Segundo a Secretaria Executiva do Conselho Nacional de Segurança Alimentar e Nutricional nunca se tratou do tema específico do direito à alimentação das pessoas privadas de liberdade nas atividades do Consea, muito embora se considere sua importância ${ }^{23}$.

Nas Conferências Nacionais de Segurança Alimentar e Nutricional realizadas, em $1995\left(1^{\mathrm{a}}\right), 2004\left(2^{\mathrm{a}}\right), 2007\left(3^{\mathrm{a}}\right), 2011\left(4^{\mathrm{a}}\right)$ e $2015\left(5^{\mathrm{a}}\right)$ foram definidas propostas, ainda que

\footnotetext{
${ }^{23}$ BRASIL. Presidência da República. Secretaria do Conselho Nacional de Segurança Alimentar e Nutricional (Consea). Informações [mensagem pessoal]. Mensagem recebida por <dunckmagni@gmail.com> em 6 mar. 2017.
} 
gerais e indiretas, relacionadas a concretização do direito à alimentação dos presos. $\mathrm{Na} 2^{\mathrm{a}}$ e $3^{\mathrm{a}}$ Conferência foram propostas ações de avalição e indicadores nutricionais de grupos institucionalizados (creches, escolas, hospitais, presídios etc) e discutida a priorização e regulamentação de compra de alimentos oriunda do público do Programa Nacional de Fortalecimento da Agricultura Familiar (Pronaf), assegurando a abertura do mercado institucional às famílias de agricultores. $\mathrm{Na} 4^{\mathrm{a}}$ Conferência, em 2011, um dos desafios propostos para garantia da segurança alimentar é a superação do racismo institucional. $\mathrm{Na}$ última Conferência, em 2015, fixou-se como meta a ampliação dos programas governamentais de produção e compra de gêneros alimentícios regionais da agricultura familiar e camponesa para a melhoria da qualidade dos alimentos servidos nas escolas, creches, hospitais, presídios e centros universitários.

Nas conferências não se discutiu políticas públicas especificas para o grupo de pessoas institucionalizada nos presídios.

A proposta de priorizar e regulamentar a compra de alimentos da produção oriunda do público do Pronaf é relevante, mas deve ser elaborada dentro de uma política pública especifica para o sistema prisional que leve em consideração as condições socioeconômicas das diversas regiões do País.

O reconhecimento na $4^{\text {a }}$ Conferência da existência e necessidade de superação do racismo institucional é marco importante para elaboração de políticas públicas efetivas. Não é demais afirmar que, infelizmente, tudo indica que o racismo institucional ${ }^{24}$ relativo às pessoas privadas de liberdade encontra-se incrustado em quase todas as Instituições do País, inclusive no âmbito do Sisan.

Desse modo, a concretização do direito humano à alimentação adequada para as pessoas privadas de liberdade, no cárcere, passa, primeiramente, pelo reconhecimento e superação do racismo institucional.

As "Instituições de Justiça" 25, e.g., Administração Penitenciária, Poder Judiciário, Ministério Público, Advocacia Pública e Privada, Defensoria Pública, Ministério da Justiça, Conselho Nacional de Política Criminal e Penitenciária, Conselhos da Comunidade da

\footnotetext{
${ }^{24}$ Racismo institucional é o fracasso coletivo de uma organização para promover um serviço de qualidade, apropriado e profissional as pessoas por causa de sua cor, cultura ou origem étnica, sendo detectado como um processo de discriminação por preconceitos involuntários, ignorância, negligência e atitudes racistas, causando desvantagens a esse grupo especifico [...]. Atuando de forma difusa no funcionamento cotidiano de instituições e organizações, provocando desigualdade na distribuição de serviços, benefícios e oportunidades aos diferentes segmentos da população do ponto de vista racial (KALCKMANN (2007); LÓPEZ L.; (2012); SANTOS (2010) apud RODRIGUES; BARROS, 2014).

${ }^{25}$ Entendida nesta pesquisa como organizações, públicas ou privadas, com atuação na área de direitos das pessoas.
} 


\section{A EFETIVIDADE DO DIREITO HUMANO À ALIMENTAÇÃO ADEQUADA ÀS PESSOAS PRIVADAS DE LIBERDADE NOS CÁRCERES BRASILEIROS E O PAPEL DAS INSTITUIÇÕES DE JUSTIÇA}

Execução Penal, Conselhos Penitenciários, Pastoral Carcerária etc, devem sugerir e participar da elaboração de políticas públicas especificas que asseguram o direito à alimentação ao grupo de pessoas institucionalizada nos presídios. A participação deve ser no âmbito do Sisan, em conjunto com os Conselhos Nacional, Estaduais e Municipais de Segurança Alimentar e Nutricional e Conferências Nacionais de Segurança Alimentar e Nutricional realizadas a cada quatro anos, bem como exigir e viabilizar a participação das pessoas presas que serão atingidas por tais políticas. A participação democrática nos conselhos e conferências se justifica para legitimar e discutir o significado do direito humano à alimentação adequada no cárcere, com base nas diretrizes da Lei Orgânica de Segurança Alimentar e Nutricional (Lei 11.346/2010).

As "Instituições de Justiça", ademais, devem zelar jurisdicionalmente pela observância do direito à alimentação das pessoas privadas de liberdade, especialmente diante da positivação deste direito no Brasil, desde 1992, observando-se as disposições da Lei Orgânica da Segurança Alimentar e Nutricional (Losan, 11.346/2006) e a Constituição Federal (art. $6^{\circ}$, caput).

\section{Considerações finais}

A análise da efetividade do direito humano à alimentação adequada às pessoas privadas de liberdade pressupõe, primeiramente, a existência de políticas públicas especificas que visem a realização deste direito e, em seguida, aferir se tais políticas são efetivas na concretização deste direito na realidade social deste grupo de pessoas institucionalizadas nos presídios brasileiros.

Apesar da positivação do direito à alimentação na legislação do País, desde 1992, da criação do Sistema Nacional de Segurança Alimentar (Sisan), em 2006, e da inclusão da alimentação no rol dos direitos sociais na Constituição Federal (art. $\left.6^{\circ}, c a p u t\right)$, conclui-se que, de acordo com o relatório do CNJ, que abrange 2010-2011, as pessoas privadas de liberdade nos cárceres brasileiros não gozam de uma alimentação adequada.

Resta deslumbrar, então, quais variáveis impedem a elaboração de políticas públicas especificas para concretização desse direito. Conclui-se ainda que uma delas, o racismo institucional, deve ser considerado. Por meio dele se legitima a violação dos direitos destas pessoas vistas como "diferentes" e "indesejadas" pela sociedade. Ele permite que a consciência de identidade entre todos os seres humanos seja deturpada e, assim, viabiliza 
socialmente a destruição do outro pela fome, ou subnutrição, obstando a elaboração de políticas públicas especificas para esse grupo de pessoas institucionalizadas nos presídios do País.

As Instituições de Justiça, portanto, devem corroborar para construção do significado e alcance do direito humano à alimentação adequada no bojo do Sistema Nacional de Segurança Alimentar e Nutricional e, paralelamente, exigir, jurisdicionalmente, a concretização desse direito na realidade das pessoas privadas de liberdade. Negar o direito à alimentação adequada a qualquer pessoa, esteja ou não privada de sua liberdade pelo Estado, é negar a identidade humana entre todos os seres humanos, é olvidar que ninguém está imune ao sistema criminal.

\section{Referências bibliográficas}

BRASIL, Constituição (1988). Constituição da República Federativa do Brasil: promulgada em 5 de outubro de 1988. Diário Oficial da República Federativa do Brasil. Brasília, 5 out. 1988. Disponível em: <www.planalto.gov.br>. Acesso em: 11.08.2016.

, Emenda à Constituição n. ${ }^{\circ}$ 64, de 4 de fevereiro de 2010. Altera o art. $6^{\circ}$ da Constituição Federal, para introduzir a alimentação como direito social. Diário Oficial da República Federativa do Brasil. Brasília, 05 fev. 2010. Disponível em: $<w w w . p l a n a l t o . g o v \cdot b r>$.

Lei Federal n. ${ }^{\circ} 11.346$, de 15 de setembro de 2006. Cria o Sistema Nacional de Segurança Alimentar e Nutricional - SISAN com vistas em assegurar o direito humano à alimentação adequada e dá outras providências. Diário Oficial da República Federativa do Brasil. Brasília, 18 set. 2006. Disponível em: <www.planalto.gov.br>.

, Lei Federal n. ${ }^{\circ}$ 7.210, de 11 de julho de 1984. Institui a Lei de Execução Penal. Diário Oficial da República Federativa do Brasil. Brasília, 13 jul. 1984. Disponível em: $<w w w . p l a n a l t o . g o v \cdot b r>$.

Decreto n. ${ }^{\circ}$ 591, de 06 de julho de 1992. Atos Internacionais. Pacto Internacional sobre Direitos Econômicos, Sociais e Culturais. Promulgação. Disponível em: <http://www.planalto.gov.br/ccivil_03/decreto/1990-1994/d0591.htm>.

Conselho Nacional de Justiça (CNJ). Mutirão carcerário. Raio-X do sistema penitenciário brasileiro. 2012. Disponível em: <http://www.cnj.jus.br/images/pesquisasjudiciarias/Publicacoes/mutirao_carcerario.pdf $>$

Conselho Nacional de Política Criminal e Penitenciária. Resoluções. Disponível em: < http://www.justica.gov.br/seus-direitos/politica-penal/cnpcp-1/resolucoes/resolucoes $>$.

CASTRO, Josué de. Geografia da fome, o dilema brasileiro: pão ou aço. $10^{\mathrm{a}} \mathrm{ed}$. Rio de Janeiro: Civilização Brasileira, 2010. 


\section{A EFETIVIDADE DO DIREITO HUMANO À ALIMENTAÇÃO ADEQUADA ÀS PESSOAS PRIVADAS DE LIBERDADE NOS CÁRCERES BRASILEIROS E O PAPEL DAS INSTITUIÇÕES DE JUSTIÇA}

EIDE, Asbjorn. A realização dos direitos econômicos, sociais e culturais. O direito à alimentação adequada e a estar livre da fome. p. 207-260. In: VALENTE, Flávio Luiz Schieck (org). Direito humano à alimentação: desafios e conquistas. São Paulo: Cortez, 2002.

FARIA, Adriana Ancona de; DIAS, Roberto Baptista. Direito à alimentação, transferência de renda e progressividade: o caso do programa bolsa família no Brasil. Revista Jurídica da Presidência. v. 18, n. 114 (2016). DOI: http://dx.doi.org/10.20499/2236-

3645.RJP2016v18e114-1210

ROCHA, Eduardo Gonçalves. Direito à alimentação, estado democrático de direito e participação popular. Saúde em Debate, vol. 34, núm. 84, 2010, pp. 67-77, Centro Brasileiro de Estudos de Saúde Rio de Janeiro, Brasil.

RODRIGUES, Deusirene Sousa; BARROS, Marcela Milrea Araújo. Racismo institucional e desigualdades sociais no brasil: um olhar para a universalidade no sistema único de saúde. Revistas Científicas do Curso de Enfermagem. Edição maio/2014. Disponível em: < http://www.revistaintertexto.com.br/ler_artigo.aspx?id=69>

TAKAGI, Maya. A implantação da política de segurança alimentar e nutricional no Brasil: seus limites e desafios. Campinas. Tese (Doutorado em Economia). Unicamp, 2006. Disponível em: http://repositorio.unicamp.br/jspui/handle/REPOSIP/286223

TOMAZINI, Carla Guerra; LEITE, Cristiane Kerches da Silva. Programa Fome Zero e o paradigma da segurança alimentar: ascensão e queda de uma coalizão? Revista de Sociologia e Política. V. 24, N. 58 (2016). DOI 10.1590/1678-987316245801.

VALENTE, Flávio Luiz Schieck (org). Direito humano à alimentação: desafios e conquistas. São Paulo: Cortez, 2002.

ZIEGLER, Jean. Destruição em massa: geopolítica da fome. Trad. José Paulo Netto. São Paulo: Cortez, 2012.

ZIMMERMANN, Clóvis Roberto. Os programas sociais sob a ótica dos direitos humanos: o caso do bolsa família do governo lula no brasil. SUR - Revista Internacional de Direitos Humanos, N. ${ }^{\text {4 }}$, Ano 3, 2006. http://dx.doi.org/10.1590/S1806-64452006000100009 